\title{
I'd Rather Play the Saxophone: Conflicts in Identity Between Vietnamese Students and Their Parents
}

\author{
Joseph Stimpfl \\ University of Nebraska-Lincoln \\ and \\ Ngoc H. Bui \\ University of Nebraska-Lincoln
}

\begin{abstract}
Members of the Vietnamese community in Lincoln, Nebraska range in time of resettlement, background and experience in adjustment to their new home. The impact of cultural change and education on the Vietnamese youth in this community is of particular importance. The Vietnamese youth are under-examined in the areas of adjustment and identity formation. The effects of cultural conflict have profound impact on the future of Vietnamese youth. The following study presents an examination of the variables that may affect Vietnamese youth, specifically culture and education as factors in ethnic identity formation. It also presents how these factors can affect the relationship between students and parents.
\end{abstract}

\section{Introduction}

The degree to which Americans value education in the United States is reflected in the extensive funding that supports American schools. However, the interpretation of "value" varies greatly among education's supporters. Often conflicting interpretations of value are evident in public discussions of what should be taught in school, why it should be so and what goal or result is important. The conflict is most clear in discussions of the social versus academic roles of schools. There are, without a doubt, as many who espouse the social and cultural aspects of schools as those who emphasize their academic elements. But 
this may be a false dichotomy. In fact, most Americans are equally concerned with both the social and cultural aspects of education and the academic value of attending school.

An interesting relationship that researchers have yet to examine is the process of ethnic identity formation of Southeast Asian students, the smallest of the immigrant Asian groups, and effects of this process on the students' and their parents' perceptions of the values of education, both socially and culturally.

This study attempts to examine the impact of culture and education on Vietnamese youth in an average-sized mid-western city. Also, the study seeks to delineate the role of ethnic identity in school performance and behavior, as well as what issues the influence of schools and family raise. First, a brief overview of the arrival of Asians, more specifically Southeast Asians, in the U.S. will be covered. Second, the importance of ethnic identity and its role in the education of minority youth will be examined. Third, the authors will present interview data of Vietnamese students and parents, including their perceptions of the roles that culture, education and family play in their lives. Also in this study, how schools may possibly impact these students' cultures will be discussed. Finally, current theoretical explanations, within a psychological framework, will be offered to help identify why these patterns of interactions occur and their possible implications on the future of the education of Southeast Asians in this country.

How do Vietnamese parents view American schools? What values do they put on education? Are there conflicts inherent in the juxtaposition of American views of education and those of the Vietnamese? If there are conflicts, how do these conflicts affect Vietnamese students? What strategies do Vietnamese students employ to deal with the transition from traditional Vietnamese households to the American school? The authors hope to answer these and other questions concerning Vietnamese students and their parents.

\section{Demographics}

According to the U.S. Bureau of Census, Asian American and Pacific Islander populations in 1990 comprised approximately $4 \%$ of the total U.S. population. ${ }^{1}$ Of these included in the census, the largest population of Asian Americans in the United States are Chinese, of which a little more than half $(56 \%)$ were foreign born. ${ }^{2}$ The earliest Asian immigrants to arrive in the United States were the Chinese, who played significant roles in the construction of this country, more specifically, this country's transportation system (e.g., the transcontinental railroad). Their arrivals are estimated to have begun around the middle of the nineteenth century. Currently, there continues to be small influxes of Asian immigrants to the United States every year, especially from the South- 
east Asian countries of Vietnam, Thailand, Cambodia and Laos. ${ }^{3}$ The most recent arrivals of Asian Americans and Pacific Islanders are those immigrants from the countries of Cambodia, Laos and Vietnam. The recent groups have more than $80 \%$ of their population foreign born. These data suggest that although the Asian American population is relatively small, the importance of examining issues such as cultural adaptation and ethnic identity formation is quite obvious for the mere fact that the Asian Americans' presence in this country is well established and because these groups are often overlooked in terms of psychological and social services mainly due to their smaller numbers and poorer skills in English and in adapting to their new culture. However, there is a significant difference between recent arrivals and the established Asian American population. There is also a real and meaningful difference between refugees who are by definition not voluntary immigrants and immigrants on whom the vast majority of the research on immigration has been based.

In this particular study, Lincoln, Nebraska, an average-sized midwestern city, was the location of the research. There are about 3,000 Vietnamese living in the area of Lincoln, Nebraska. ${ }^{4}$ Although most are refugees and have been here less than three years, the resettlement of the Lincoln Vietnamese has taken place over a 15 year period, so at any time there are a range of experiences and attitudes in the community. Some of the refugees that have been resettled here for the longest time now have children beginning college and who were born in the United States. However, the largest number of Vietnamese students in Lincoln schools were born in Vietnam.

This paper is based on interviews with 10 sets of parents and 10 Vietnamese college students conducted in 1993-1994. All informants were interviewed individually using an unstructured interview format based on a generalized interview protocol designed to ascertain informant views on school experiences, both personal and ethnic identity, and family relationships. Interviews were extensive and follow up interviews were often conducted to clarify or expand issues raised in initial interviews. Informants included long term residents of the Lincoln area, newer arrivals, students born and mostly raised in Vietnam, and others born in the United States or immigrated when they were very young. Findings were discussed with Vietnamese prominent in the community, officials who work in social services, and educators who specialize in minority school problems. This study is part of an ongoing study of Vietnamese parents and children in Lincoln, Nebraska. The ongoing study deals with changes in ethnic identity and considers the various factors that may impact ethnic identity formation and change among Vietnamese. The emphasis is on children and schools but includes other mechanisms and processes that impact ethnic identity. 


\section{Ethnic Identity}

Ethnic identity serves as an important contributing factor to the overall relationship between Vietnamese children and their parents, not only because different concepts of ethnic identity can serve as sources of conflict, but also because it can perform as a means for individuals to feel a sense of commonness and belonging with others and in this way may provide a psychological function. ${ }^{5}$ The features of this psychological function are that ethnic identity: 1) includes the general knowledge, beliefs, and expectations that a person has about their ethnic group, 2) serves a cognitive function in that it offers an information-processing framework or filter within which one can interpret and perceive objects, situations, events, and other people, and 3) functions as a foundation for a person's behavior. Furthermore, ethnic identity has been identified as playing particularly salient roles in such psychological processes as cultural adaptation and acculturation, ${ }^{6}$ generational conflicts within families, ${ }^{7}$ and psychological adjustment and stress of refugees. ${ }^{8}$ Consequently, ethnic identity is specifically important to Asian immigrants, because Asians, especially refugees, are the most recent arrivals to America and their relatively low numbers and distinct physical characteristics that limit alternative group membership demand solidarity and ethnic identity. In addition, the issue of ethnic identity is believed to be an important factor in the relationship between Asian American parents and their children. From studies with college students and high school students ${ }^{9}$ the process of ethnic identity development is a significant factor in understanding the self-esteem and adjustment of minority youth, which ultimately leads to increased understanding of other relationships in their lives, in this case, their family members.

Several models have been developed to describe the formation of ethnic identity. These include the Identity Formation Model, ${ }^{10}$ the Minority Identity Development Model, ${ }^{11}$ and the Stages of Ethnic Identity. ${ }^{12}$ It is noticeable how most of these models describe similar, if not overlapping, stages of identity development.

\section{Identity Formation Model}

According to Marcia, ${ }^{13}$ identity formation is the process of combining the multiple selves that the individual has developed for themselves and forming a coherent whole self. The main issue of identity for the individual is to achieve some sort of internal consistency. Based on Erikson's theory of ego identity formation, ${ }^{14}$ Marcia formulated the four Ego Identity Statuses: 1) identity diffusion; 2) identity foreclosure; 3) moratorium; and 4) identity achievement. Beginning with the first status, identity diffusion is the status of a person who has neither engaged in exploring nor made a commitment to some form of identity area, such 
as occupation, religion or political affiliation. Someone who has made at least some commitment to an area that may define their identity but who has not gone on to explore their identity and these areas is said to be in the foreclosed status. Having not made a commitment, but in the process of exploring is known as the moratorium status. Finally, a person who has made a firm commitment following a period of exploration is best described as one who has an achieved identity status. This theoretical model of identity formation relates to ethnic identity formation in that it closely ties to the minority person's experiences with commitment to an identity area as well as their exploration into these areas, in defining the role of ethnicity in their lives.

\section{Minority Identity Development Model}

Asians fit the definition of differentiated minority because they receive differential and unfair treatment, not to mention exclusion from certain aspects of American life, due to their physical and cultural traits. 15 As such, the model of Minority Identity Development may applicably describe the formation of Asian ethnic identity. The model's first stage begins with one termed the Conformity Stage. This stage entails the adoption of cultural values and lifestyles of Euro-Americans, as well as also having the person, consciously and unconsciously, degrade and denigrate the physical and cultural characteristics of their own minority group. This was hypothesized as individual efforts to try to elevate his or her personal status by identifying with members of the dominant group. Following the Conformity Stage, the second stage in which Asian Americans experience ambivalent feelings aboutboth the dominant group and his or her own minority group is called the Dissonance Stage. This ambiguity is hypothesized to be due to the information and experiences that individuals have encountered that may be inconsistent with their previously accepted dominant group values and beliefs causing them to question their aspiration of membership in the dominant group. In the third stage of Minority Identity Development, minorities totally reject the dominant group and exclusively embrace their own minority culture. This stage is known as the Resistance and Immersion Stage. The individuals show unquestioning acceptance of their group's cultural values and begin to question why they experienced shameful feelings about who they are. The minority develops a great deal of identification with and commitment to other members of his or her minority group as well as an interest in exploring his or her culture and history. At the fourth stage of Introspection, individuals feel sufficiently secure about their identity to begin to question their previously held strong beliefs. Minorities will hold secure individual identities as members of minorities but also recognize some positive elements in the dominant culture. The fifth and final stage for minorities in developing ethnic identity is the Synergetic Articulation 
and Awareness Stage. In this stage, they accept or reject the cultural values of the dominant and minorities groups on an objective basis and have a feeling of self-worth and individuality.

\section{Stages of Ethnic Identity}

Similar to the Minority Identity Development Model of Atkinson et al., Phinney suggested a three stage movement toward identity formation. Phinney's proposed stages include the periods from an unexamined ethnic identity, through a period of exploration, to an achieved or committed ethnic identity. In the first stage of unexamined ethnic identity, Phinney hypothesized that younger adolescents, and maybe also some adults who experience this stage, have not had normal ethnic group experiences. The result may be that individuals could show a preference for the dominant culture. ${ }^{16}$ In the second stage of exploration, the person begins to discover his or her own ethnicity. This second stage is similar to the moratorium status described by Marcia ${ }^{17}$ in the model for identity formation. However, this stage describes a more intense process of voluntary immersion in one's own culture through various activities, such as reading and learning about one's culture. In addition, individuals may also experience rejection of the values of the dominant culture. This suggests that as a result of the process of ethnic identity formation, people can come to a deeper understanding and appreciation of their own ethnicity, which is described in Phinney's third stage of committed ethnic identity, and they also experience ethnic identity achievement or internalization.

Models developed to explain ethnic identity formation are usually formulated specific to one ethnic group, usually one with a clearly defined identity in the American context. These models will have differing degrees of relevance to individual Vietnamese who include both immigrants and refugees, and their children. This is particularly the case in families whose children have different experiences based upon place of birth and number of years resident in Vietnam.

\section{Cultural Dilemmas}

At some point in the context of their schooling, Vietnamese children must make the choice whether they will maintain strong cultural behavior and norms in the face of peer pressure or conform to the expressed cultural system of their American peers and face possible family disapproval. This is similar to the stage of Marcia's Identity Formation Model, known as the moratorium stage, the second stage of the Minority Identity Development Model of dissonance, and also Phinney's second stage of ethnic identity. At this stage it is a difficult choice to make between family and peer expectations, and one that forces children to make 
determinations of cultural value and preference. Factors that seem to affect the decision are the individual's age at the point of transition from one culture to the other, the number of Vietnamese in the community and school and the point at which the identity choice must be made.

This can be exacerbated by dominant group perceptions of Vietnamese. For some time there has been a perception that the Vietnamese, like other Asian groups, are a "model minority." However, research in Nebraska and other places ${ }^{18}$ indicates that, although there is a large number of Vietnamese students who have very successful academic records and go on to universities, there is also a significant number who do not have great academic success. Recently it has become clear that many disaffected Vietnamese children are running away ${ }^{19}$ or becoming involved in gangs. 20 There is evidence in the emerging literature of the American experience of Vietnamese immigrants that there is a disturbing maladjustment among Vietnamese adolescents. ${ }^{21}$ Perhaps, for the Vietnamese adolescent, their maladjustment may be due to the exploration and stagnation they are experiencing in the beginnings of ethnic identity development.

\section{Vietnamese Adolescents and Family Values}

The Vietnamese family is characterized by a patrilineal and patriarchal structure, with extreme centrality and pooling of resources through a highly disciplined extended family system. 22 Vietnamese describe themselves as hardworking and industrious, with a relentless drive to be successful. ${ }^{23}$ Core values include filial piety, mutual obligation to family, politeness, modesty and humility. Primary responsibility is to the family lineage: family interests should be put before personal interests.

Like other Southeast Asian groups, Vietnamese allow very young children considerable freedom in behavior. However, after children reach the age when they begin to understand abstract concepts and communicate freely, parents often impose a strict standard for behavior.

Adolescents are expected to fulfill their responsibilities to family and family lineage. With the onset of adolescence, girls are expected to manifest modesty, obedience, chastity. Boys are expected to exhibit adult male behavior. Family members are expected to share in household tasks to the extent of their abilities.

Of course this is an area of contention for Vietnamese children raised in America.

Adolescents in Vietnam have had little choice in moral 
values. Traditionally, culture and society have reinforced the morality taught in the family. However Vietnamese coming to this country often find that their traditional family values are inconsistent with those in American society. ${ }^{24}$

The autonomy and independence of American youth conflict with Vietnamese cultural values. The strong influence of Confucianism on Vietnamese society and its emphasis on obligation and hierarchy contrast with the individualism that is a predominate characteristic of American society. 25 In Vietnam, parents usually have major role in or absolute control of the decisions of adolescents. As one student explained to us, "Vietnamese kids are expected to obey their parents in every way." However, more and more Vietnamese adolescents are refusing guidance from parents or making decisions without parental advice. 26 Following the ethnic identity models, part of their research for an identity in a newly adopted setting, such as the U.S., there poses much conflict in what the adolescents view as being "American" and what they view as "Vietnamese."

\section{Conflicts}

The conflict is most clearly evidenced in the practice of strong peer identification in American children versus the "greater emphasis on achieving one's identity and sense of worth through close relationships with family adults and being a member of an established lineage and extended-family system" 27 for Vietnamese. Vietnamese traditions promote family cooperation. The dynamics of the Vietnamese family hinder the development and expression of the kind of individualism that Americans see as appropriate.

Virtually all Vietnamese parents interviewed recited the same litany of expediency: the most important thing for children is to learn English and perform well in school. School performance will insure career tracking that will result in success, in this case defined as the accumulation of capital, acquisition of material goods and rise in status for the family. ${ }^{28}$ Anything that was not related to this was considered to have little or no importance. As one Vietnamese university student explained, "All they want us to do is stay home and hit the books." Many Vietnamese parents view education as their children's prime source for success and achievement in America and fear that socializing and dating could possibly take away from their studies. ${ }^{29}$ As one father explained, "I want my son to do only what is important. Not waste time with friends every evening." The concept of "dating" was a particular point of contention. When describing what her parents' views on dating were, a student said that they told her, "no dating until finishing school. 
And no dating non-Vietnamese, ever." A female Vietnamese graduate student explained that her parents, although relatively successful and both with post-secondary educations, felt very strongly about her plans for a marriage partner. It was well known in the community that they had directed her to choose a Vietnamese male as a prospective marriage partner. For this reason, even though she was dating and planned to marry a European American, she attended Vietnamese functions with a Vietnamese male friend. "I am not yet in a position to confront them with my future plans. The difficulty is that I can't find a Vietnamese man with a university education." Another student repeatedly mentioned his father's beliefs on education and the potential for conflict.

He really stresses education. He hears I've been dating, but he wants me to only have friends. I don't think he can ask that. I have to do what I want. I don't think he understands it. He will never accept it.

Control of children and the effects of their behavior is considered the responsibility of the family. Undesirable behavior reflects negatively upon the entire family. Most parents do not pressure schools and teachers to cooperate in their definition of success. Unlike other longer resident American minority parents, the Vietnamese want to avoid expression of disagreement with public officials.

My children are supposed to go to school and learn. In this way they can get a good job or even go to the university and learn a career. Anything that gets in the way of this is not good. I don't want trouble in school. It is better if we are left alone. Then my children can devote their time and attention to their studies. 30

The idea of the cultural and social value of education makes little sense to these parents. For example, to nearly every parent interviewed, the idea of "multiculturalism" was considered unimportant. The majority were not even familiar with the concept even though it had been the subject of heated local public debate for some time. As one parent explained,

We Vietnamese are homogeneous. We don't discriminate but we don't mix either. We don't mind those others. I work with them and they are my friends. But they don't have anything to do with our lives.

Perhaps isolation and unobtrusiveness are survival tactics for a group 
Ethnic Studies Review, Vol. 19, No. 1

that has been long penalized for any expression of difference. "Under the communists you aren't supposed to be different, uncooperative. We don't want to cause trouble." 31 Avoidance of involvement leads to community isolation which extends to not involving schools in family or home problems. As one Vietnamese community leader explained to us, "school is not able to handle their problems. We must take care of things ourselves. Parents are confused, don't understand, or even disapprove of what goes on in the school, but parents are very hesitant to complain to teachers."

Cross-cultural problems for both parents and children crop up as a result of the emphasis on unobtrusiveness early on in resettlement. Parents recognize that success for children will depend on how well they "fit in." Initially, immigrant parents cooperate fully in the "Americanization" of their children. "We want them to be American. We encourage it. After all, we are in America."32 The initial goal, to "fit in," is soon mitigated by a growing understanding of the differences between Vietnamese and American culture, 33 and the effect of American culture on their children.

New arrivals are very enthusiastic. But after a while they see the life here is very different. They recognize that activities are not community based. They see that Americans are often isolated and that Vietnamese who are "too American" may distance themselves from the community. 34

Another difficulty is in the discipline practices. "Children are like bamboo. Without control it will grow any which way. You must bind it up until it grow tall. Only then will it be straight and good." 35 Vietnamese are not used to children who are uncooperative, disrespectful or disobedient. Many parents are concerned with what they consider to be lax discipline in school and believe that it has resulted in a lack of respect for parents. ${ }^{36}$ They believe children need strict discipline to become responsible adults. The preferred punishment is corporal. "I spank them when they really do very bad things-impoliteness, fighting, being too stubborn and so on." 37 It is a common joke among Vietnamese, which we heard several times in a variety of settings, that they are afraid that if they punish their children in a traditional manner, the children will call emergency 911 to report their parents to the police. Parents are also quick to point out that this is what children have been taught in school. It is clear that many Vietnamese do not understand the school's need to "interfere" in family relationships.

For parents whose children are born in the United States or attended most of their schooling here, problems often begin to appear around the time of adolescence, when Vietnamese children are expected 
to begin to adopt the roles of adults.

Okay there is some breakdown in the family. Kids are growing and becoming American. They want to date. They want to go out. This idea never existed in Vietnam. So the kids cannot tolerate this. And they don't like to be told- anything, particularly to stay home. ${ }^{38}$

Even the best behaved and properly enculturated students are subject to attitudinal differences that are emphasized in school. Individualism and individualized personal growth as expressed in American culture are not familiar characteristics to Vietnamese parents.

I want to please my parents but they just don't see things the way that I do. I got interested in art in school. My father wanted me to be a doctor. So now I am at the university and I am taking pre-med courses, but also art courses. I haven't told them I'm not going to be a doctor. It was the same thing with music. I told my mother I wanted to study music when I was in high school. She asked me to play the piano. I was afraid to tell her, but I didn't want to play the piano. All I wanted to do was play the saxophone. 39

We found some evidence of this conflict in every household we interviewed. However, it was not always apparent to an outsider. Vietnamese students who are older when they arrive, seem to have the best record of success. They either go on in school or go to work and contribute to family household costs, turning over paychecks to male headsof-households. Vietnamese who were younger when they arrived, particularly males, often have outright conflicts with parents over such matters as spending money, associating with less desirable friends, and staying away from home too much, often spending nights with friends. This finding has been reinforced by the recent introduction of Asian gangs into the community. The gangs are composed mostly of disenfranchised and dissatisfied males.

\section{Ethnicity and the Difficulties in Schools}

Choice of affiliation and identity formation can also be influenced by the dynamics of group interaction in schools. This may be beyond the control of the students themselves. If there are very few Vietnamese in the school, children might suddenly find themselves disenfranchised from the majority when ethnic differences begin to be realized by other students. If there is a larger group of Vietnamese, they may find 
themselves relegated to "being Vietnamese," regardless of their identity preferences. In some school experiences, particularly when there are no other Asians present, the issue might not arise at all. As in the case of some Vietnamese students, the question of ethnic identity did not arise until they arrived at the university. West High School (a pseudonym) is in a traditional European-American blue-collar neighborhood. Up until a few years ago, minority students had tended to choose to go to other high schools were there were more minority students. According to local school district policy, because of low representation of minorities, West High School was encouraged to take measures to increase its number of minority students. The result was a dramatic influx of Vietnamese students. Although there had been a few Vietnamese students previously, they had either fit into the student body or remained on the margins of school life and activities and been largely ignored.

The increased number of Vietnamese, many of them immigrants, resulted in greater viability of Vietnamese culture. Vietnamese students tended to socialize together and, most tellingly, spoke Vietnamese in social contexts. This created tension, particularly among those children who were not familiar with schooling in cross-cultural contexts, a very common instance in Nebraska. The tension reached a crisis point over the use of Vietnamese language in school. Some students felt that the Vietnamese students were being "exclusive" and not trying to "fit in" because they tended to stay together, particularly in the lunch room, and speak Vietnamese. One white male student objected to a Vietnamese student whom he said was "staring" and "smiling" at him. This was clearly a cross-cultural miscue. In Vietnam, the smile can mean anxiety, anger, fear, embarrassment and even disagreement. It is a public face to cope with all difficult circumstances.

The resultant tension led to epithets being painted on school walls and a series of incidents of name calling. The principal, clearly shaken by the events, tightened security, instituted a dress code and prohibited groups that had the "appearance of gangs." These measures applied to the Vietnamese students as well as the groups who threatened them. The result was that social interactions of groups of Vietnamese students and other minority students were discouraged. One Vietnamese student said, "These things are really just to make us be like them."

This situation has had several repercussions. At West High, Vietnamese students are no longer free to choose between an identity based on Vietnamese culture or assimilating into American culture. Those American students who find Vietnamese culture unattractive have polarized the Vietnamese and classified all students of Vietnamese origin as, according to several teachers, "chinks." In this type of situation, it may be difficult to be successful. $\operatorname{Sin}^{40}$ found that refugee students who are able to retain some of their native, home cultural values, while 
also learning to blend into the mainstream culture, record higher academic achievement in school. Such students have a commitment to academic achievement, a strong sense of self-esteem and a clear ethnic self-concept. However, Vietnamese students do not always fit this profile.

\section{Lincoln Vietnamese and their Community}

Although lumped into a generic category by outsiders, the Lincoln Vietnamese community is not homogeneous. There are many differences among Vietnamese including such things as religion, affiliation in Vietnam, place of origin, occupation, experience and social status. Since family is so important, family problems are not readily discussed outside the immediate family. However, some support for community problems is offered to Vietnamese through a variety of social and religious groups. Virtually all Vietnamese belong to one or more of these groupings, which may include, among others, the Catholic church, a variety of Protestant groups, a Buddhist temple and veterans of the Army of the Republic of Vietnam (ARVN). Such organizations claim that problems with the community are caused by outsiders, particularly those disenfranchised from group membership by life experiences, wartime affiliation, ethnicity, marriage or "immoral" or socially inappropriate behavior. For example, many Vietnamese in Lincoln belong to the Catholic church, which provides support but also describes morality and prescribes behavior.

In one case a Vietnamese teenager was caught shoplifting. The manager of the store took him into his office and told him he was going to call his parents. In most circumstances the preference would be to call parents over the police. However, the Vietnamese boy drew a gun and escaped from the store. He was later arrested by the police. He explained that when he realized that his shoplifting would cause his family embarrassment, he could think of nothing except to run away. As his mother explained, he "did not want to have his father find out. He did not want to shame my family."

Commonly broken or weak families are blamed for many problems in the Vietnamese community. To traditional Vietnamese, not having a family is unthinkable. 41 "The worst thing that can happen to a Vietnamese is to embarrass or lose his family. Without family you are no one." 42

If you look at any of the problems of Vietnamese children, they are all related to one thing: broken families. Either the child comes from an unmarried mother, is an adopted child from a first marriage or is adopted because there are no parents. These are the problem 
children. Vietnamese do not make good step-children

or step-parents. Nobody is happy with these children. 43

Such children are mentioned as an embarrassment to the community. One Vietnamese mother referred to these children as "dust children." They have no one and no place to call home, they have no value or stability. Another parent said that most of such troublesome children come from California. In fact, it is commonplace to blame Lincoln youth troubles to outsiders.

They really are trouble. I don't like them here. I wish that they would stay in California. Children from broken homes are a bad influence on other children. They loaf around and don't do anything. And they ask other children from good homes to join them. 44

One primary school girl living with only her mother fits this classification. It is unclear why the mother is alone, but the child has no status or standing in the community. According to her teacher, she is unable to make friends with any other children. For her birthday, she was only able to invite her teachers to her party, most of whom chose not to go. Says her teacher, "she is so sad and alone. I wish I could do something, but I don't really see how. She is Vietnamese through and through. But she has no ties to that community."

\section{Students and Ethnic Identity}

Another group, now just arriving at the university, are those Vietnamese who have been raised American. They often have resisted the "immigrant culture" of their parents, choosing to think of themselves as "average Americans." Inevitably as they progress through the school system, it becomes clear that they will be denied this identity option. As peer groups begin to form, Vietnamese often become "different." This is a particular hardship on children who have grown up with the illusion of "sameness."

At some point minority children must choose some other identity option which is often exclusive in nature. Finding majority identity denied to them, these students may concentrate on school academic performance, or drop out of the system altogether. In interviewing Vietnamese students attending the university we found that many successful students had created a hybrid identity, blending social norms from both American and Vietnamese culture. Of particular note, the students interviewed shared their parents' views of appropriate mates, by appearing to hold on to the traditional values of looking for companions who were within their own culture. Said one female university student: 
"I want to marry a Vietnamese guy. We would have cultural understanding, a basic understanding of each other."

Another female student related, "When I was younger, I wasn't in much contact with Vietnamese guys so I imagined myself marrying an American. Now my choices have broadened. I'd rather marry a Vietnamese guy." In a combination of traditional Vietnamese and American views, a Vietnamese male student described the girl he might "date," "Preferably a Vietnamese girlfriend. Before it was American. It's better for me and my family. She'd help me learn Vietnamese, the culture." For these students, cultural continuity has become quite important, not in terms of rejecting American culture, but rather preserving ethnic identity and, as one student explained, "honoring my ancestors." Consistent with our findings of marriage views, students showed an increased appreciation for their culture and heritage, even though some studies have reported that Vietnamese-American youth have exhibited less interest in their traditions and values as compared to their parents and elders. This is often in spite of tendencies they had evidenced in early adolescence to reject traditional Vietnamese cultural values.

I speak mostly English with my cousins, but recently [have been] speaking more Vietnamese. When I came to Lincoln, I wasn't thinking about my traditions. Here, I interact with more Vietnamese; they speak better. It makes me feel bad, embarrassed. I don't want to lose the language. Makes me feel left out. Makes me think about my values. ${ }^{46}$ Friends who are not Vietnamese, would ask me about my culture and I felt bad about no knowing. [This change to know more about my culture] would not have happened if I were working, if I wasn't in school. It has a lot to do with the university. Here, the setting makes you ask more questions. 47

There are implications that this appreciation for culture and heritage is a function of establishing self-identity. The time, place and circumstances of the completion of adult identity formation vary among the students. Also, these students' connections with their Vietnamese heritage are dependent upon experiences in the school setting, especially when it results in an examination of ethnic identity, often in terms of a personal or family crisis.

\section{Conclusions}

As this paper has presented, the issues impacting Vietnamese ethnic identity formation are broad and multi-dimensional. It is not surprising that there are other components to the formation of identity that 
have not been extensively explored. We have attempted to describe some of the issues concerning ethnic identity formation, including the manifestation of problems concerning ethnic identity and its effects, both positive and negative on children's cultural values. These cultural values, specifically the values inherent in American education, are strongly affected by the development of ethnic identity.

Vietnamese in Lincoln, Nebraska seem to willingly inhabit the fringes of the debate concerning the value of education. They have established an enclave as a normative reference group 48 which sets standards, offers guidance and polices behavior. They leave the decisions on curricular inclusion and education goals to others. For Vietnamese parents, the social value of education is not a high priority. To them, the broader purpose of education is to further the interests of the family. As an integral and contributing member of a family, each child has responsibility to support the welfare and status of the family. Individual excellence is rewarded when it contributes to these goals. Individualism and self-expression are tolerated only in context of achieving these goals. When such personal attributes go beyond or conflict with family well-being they are discouraged and devalued.

Unlike other predominantly European migrant groups to the United States, status and identity are anchored solely to the family. If Vietnamese wish to maintain membership in the Vietnamese community it is only possible through membership in a family. Single Vietnamese who are unable to locate extended family will seek honorary affiliation with an existing family through informal adoption. No Vietnamese will willingly exclude themselves from family membership. The strength and importance of this tie cannot be overstated. Vietnamese students must cope with the demands to be American and the constraints of traditional Vietnamese culture. The inevitable result is the beginning of a hybrid culture ${ }^{49}$ which both complements and conflicts with traditional Vietnamese culture. As children progress to adulthood they become more cognizant of their place in the larger community. Often this includes being members of the Vietnamese community and integrating into the non-Vietnamese community. For their parents, community provides a safety net of protection and support. It influences activities and helps to interpret the meanings and activities of the host culture. $50 \mathrm{In}$ contrast, this community can be a burden to children, creating conflict between new and old culture. The responsibility of membership is conformity to cultural norms of the immigrant group: no difficulty to parents, often a hardship for their children. School provides the nexus for an emerging cultural identity. The circumstances and the school will limit the identity choices and force a decision from the student. In some cases, particularly in schools where there are no other Asians, the opportunity to "pass" as a member of the majority group is available to the student. In this case the decision of identity may be deferred or ignored. 
In other cases there may be a choice between being Asian and being American or non-Asian. In Lincoln, Nebraska, Vietnamese students must cope with being "Asian," clearly and inexorably different, often in spite of the fact that this was not an issue in earlier grades of primary school. This often results in marginalizing them into an involuntary Asian identity which emerges as a hybridization of American, Vietnamese and even generalized Asian culture. From this cultural adaption conflicts emerge in the family and in both the Vietnamese and non-Vietnamese communities. Together, the examination of ethnic identity and its effects on the education of all youth should be considered carefully. This project will continue in the future to examine emerging issues in Vietnamese identity formation and track change within the Vietnamese community of Lincoln, Nebraska, comparing and contrasting the unique characteristics of this community to other Vietnamese and emerging immigrant communities in the United States.

\section{Notes}

1 Paul Ong and Suzanne Hee, "The Growth of the Asian Pacific American Population: Twenty Million in 2020," The State of Asian Pacific America, a Public Policy Report: Policy issues to the year 2020 (Los Angeles: LEAP Asian Pacific American Public Policy Institute and UCLA Asian American Studies Center, 1993), 11.

2 Laura Uba, Asian Americans: Personality Patterns, Identity, and Mental Health (New York: Guilford Press, 1994), 2.

3 Uba, 4-5.

4 Lincoln-Lancaster County Health Department, Special Public Health Report: Minority Health in Lincoln, Nebraska (Lincoln, NE: Author, 1994),

5 Jean S. Phinney, "Ethnic identity in adolescents and adults: Review of research," Psychological Bulletin 108 (1990): 499-514.

6 N. Chance, "Acculturation, self-identification and personality adjustment," American Anthropologist 67 (1965): 372-393; M. Masuda, K. Lin, \& L. Tazuma, "Adaptation problems of Vietnamese refugees," Archives of General Psychiatry 37 (1980), 447-450; E. A. Clark, \& J. Hanisee, "Intellectual and adaptive performance of Asian children in adoptive American settings," Developmental Psychology 18 (1982):595599.

7 N. Nguyen, \& H.L. Williams, "Transition from east to west: Vietnamese adolescents and their parents," Journal of American Academy of Child 
Adolescent Psychology 28 (1989): 505-515.

8 P. Nicassio, "Psychosocial correlates of alienation: Study of a sample of Indochinese refugees," Journal of Cross-Cultural Psychology 14 (1983): 337-351; A.J. Vignes \& R. Hall, "Adjustment of a group of Vietnamese people to the United States," American Journal of Psychiatry 136 (1979):

$442-444$.

9 Jean S. Phinney, "Stages of ethnic identity development in minority group adolescents," Journal of Early Adolescence 9 (1989): 34-49.

10J. Marcia, "Identity in adolescence," in Handbook of Adolescent Psychology, ed. J. Adelson (New York: Wiley, 1980), 150-187.

${ }^{11}$ D. Atkinson, G. Morten, \& D.W. Sue, "A minority identity development model," in Counseling American Minorities, ed. D. Atkinson, G. Morten, \& D.W. Sue (Dubuque, IA: William C. Brown, 1989), 35-52.

12 Phinney, 1989.

${ }^{13}$ Marcia.

${ }^{14}$ E.H. Erikson, Identity: Youth and Crisis (New York: W.W. Norton \& Company, 1968), 50-62.

$15 \mathrm{~J}$. Westermeyer, "Advances in alcohol and substance abuse," Cultural and Sociological Aspects of Alcoholism and Substance Abuse 4 (1984): 9-18.

16 Phinney, 1990.

17 Marcia.

${ }^{18}$ S.J. Lee, "Behind the model-minority Stereotype: Voices of high-and low-achieving Asian American students," Anthropology and Education Quarterly 25 (1994): 413-429.

19"America's New Wave of Runaways," Newsweek, 4 April 1994; K. Wapner, Teenage Refugees from Vietnam Speak Out (New York: The Rosen Publishing Group, 1995)

20"Asian Gang's Growing Influence," San Jose Mercury News, 4 January 1994; N. Kibria, Family Tightrope: The Changing Lives of Vietnamese Americans (Princeton, NJ: Princeton University Press, 1993), 144145. 
21 O.P. Tran, "From isolation to integration: Vietnamese Americans in Tran Dieu Hang's Fiction," in Reading the Literature of Asian Americans, ed. S. Lim (Philadelphia: Temple University Press, 1992), 280.

22K. Ima \& R.G. Rumbaut, "Southeast Asian refugees in American schools: A comparison of fluent-English-proficient and limited-Englishproficient students," in The Asian American Educational Experience, ed. D.T. Nakanishi and T.Y. Nishida (New York: Routledge, 1995), 194; P.J. Rutledge, The Vietnamese Experience in America (Bloomington: Indiana University Press, 1992), 116.

${ }^{23}$ Rutledge, 45; P.J. Strand, \& W. Jones, Indochinese Refugees in America (Durham: Duke University Press, 1985), 133.

24J.K. Matsuoka, "Differential acculturation among Vietnamese refugees," Social Work 35 (1990), 342; C.R. Finnan, "The influence of the ethnic community on the adjustment of Vietnamese refugees," in Interpretive Ethnography of Education at Home and Abroad, ed. G. Spindler and L. Spindler (Hillsdale, NJ: Lawrence Erlbaum, 1987), 319; Kibria, 99; N. Caplan, J.K. Whitmore, \& M.H. Choy, The Boat People and Achievement in America (Ann Arbor, MI: The University of Michigan Press, 1990), $42-49$.

25Kibria, 43-44.

26 Finnan; Kibria.

27Matsuoka, 343.

28Kibria, 154.

${ }^{29}$ Rutledge, 131.

30 Vietnamese parent.

31 Vietnamese mother.

32 Vietnamese mother.

${ }^{33}$ Rutledge, 61.

${ }^{34}$ Vietnamese leader.

35 Vietnamese father. 
Ethnic Studies Review, Vol. 19, No. 1

36 Kibria, 147.

37 Vietnamese father.

${ }^{38}$ Vietnamese father.

${ }^{39}$ Female Vietnamese university student.

${ }^{40}$ B.C. Sin, "Socio-cultural, Psychological and Linguistic Effects on Cambodian Students' Progress Through Formal Schooling in the United States" (Ph.D. diss., University of Oregon, 1991).

41 Kibria, 101.

42 Vietnamese leader.

${ }^{43}$ Vietnamese social worker.

${ }^{44}$ Vietnamese parent.

${ }^{45}$ Rutledge.

${ }^{46}$ Vietnamese male university student.

47 Vietnamese female university student.

${ }^{48}$ A.E. Roberts \& P.D. Starr, "Differential reference group assimilation among Vietnamese refugees," in Refugees as Immigrants: Cambodians, Laotians, and Vietnamese in America, ed. D.W. Haines (Westport, CT: Greenwood Press, 1989), 43.

${ }^{49}$ Rutledge, $58 \mathrm{ff}$. Roberts, $51 \mathrm{ff}$.

${ }^{50}$ Finnan, 326-327. 